\title{
Periodontal status of patients aged 18 living in the Lublin Province of eastern Poland
}

\author{
Ewa Trubecka-Posnik', Barbara Tymczyna', Agnieszka Haratym-Maj² \\ ${ }^{1}$ Chair and Department of Conservative Dentistry with Endodontics. Medical University in Lublin, Lublin, Poland \\ ${ }^{2}$ Department of Pathophysiology, Institute of Rural Health, Lublin, Poland \\ Trubecka-PosnikE, Tymczyna B, Haratym-Maj A. Periodontal status of patients aged 18 living in the Lublin Province of eastern Poland. J Pre- \\ Clin Clin Res. 2017; 11(1): 35-37. doi: 10.26444/jpccr/75531
}

\begin{abstract}
Introduction and Objective. Periodontitis is the one of most common chronic inflammatory diseases of the oral cavity. Periodontal disease (PD) concerns mainly adults; however, it is now increasingly seen in adolescents. The mechanism responsible for the higher prevalence of periodontal among young adults may be associated with the changes in lifestyle. Awareness of the role of proper oral hygiene and a healthy lifestyle is therefore essential for the prevention of periodontal disease in young people. The aim of the study was to assess the prevalence and severity of periodontal disease among 18 -year-old young adults from Lublin Province in eastern Poland.

Materials and method. The study group included 75 adolescents aged 18 years -50 urban and 25 rural. Periodontal status was assessed on the basis of the CPI (Community Periodontal Index).

Results. The results obtained showed that clinically healthy periodontium was found only in $26.66 \%$ of the study population. $73.34 \%$ of adolescents had periodontal problems. Healthy periodontium was observed more frequently among rural residents than among urban residents.

Conclusions. The data show that $73.4 \%$ of young adults needs to take preventive or treatment actions for periodontal diseases. It could be used as a marker for an increased risk of PD in adults.
\end{abstract}

\section{Key words}

periodontal status, risk factors, young adults, CPI index

\section{INTRODUCTION}

Periodontitis is the one of most common diseases of the oral cavity. It is a chronic inflammatory condition characterized by the destruction of non-mineralized and mineralized connective tissues. Epidemiological data indicate that in Poland, as well as worldwide, over $70 \%$ of the population suffer from some form of periodontal disease (PD) $[1,2]$. Numerous data demonstrate the relationship between periodontal and systemic diseases, such as diabetes, cardiovascular and kidney disorders $[3,4,5,6]$. Additionally, it may also be the cause of premature births and low birth weight of infants $[7,8]$.

The main cause of periodontitis is the presence of plaque and biofilm covering the teeth, dominated by Gram-negative and Gram-positive bacteria, such as Treponemadenticola, Tannarella forsythia, Prevotellaintermedia, Streptococcus sanguis, Fusobacteriumnucleatumor Helicobacter pylori [3, $4,9]$. The periodontal bacterial infection plays an initiating role in further processes leading ultimately to tooth loss [10].

Risk factors of periodontal disease, apart from poor oral hygiene, include: age, gender, systemic disorders obesity, diabetes), smoking, alcohol abuse and stress. In addition, some studies indicate a possible genetic influence on the development of periodontal disease. $[3,11,12]$. The causes of periodontal inflammation may also include incorrect filling, extensive carious defects and leaky restorations [13]

Periodontal disease concerns mainly adults [14] and develops around the age of 30, more frequently among men than women. However, neglecting oral hygiene in young

Address for correspondence: Agnieszka Haratym-Maj, Department of Pathophysiology, Institute of Rural Health, Lublin, Poland

E-mail: agamaj3@poczta.onet.pl

Received: 13 December 2016; accepted: 17 May 2017 adults, by maintaining bacterial plaque, causes inflammation that occurs despite the absence of symptoms. Inflammation can manifest itself by increased bleeding of papilla, excessive depth of periodontal pockets and gingival recession. Early symptoms of the disease, such as pain while brushing the teeth and swollen, bleeding gums are often underestimated. Therefore, the role of proper oral hygiene and a healthy lifestyle in the prevention of periodontal disease in young people should be underlined. in order to reduce the incidence of periodontal disease in adults $[14,15,16]$.

\section{OBJECTIVE}

The aim of the study was to assess the prevalence and severity of periodontal diseases among 18-year-olds from the Lublin Province of eastern Poland, based on the Community Periodontal Index (CPI). The potential cause and effect of a relationship between oral health and oral care habits among the study group were also investigated.

\section{MATERIALS AND METHOD}

Data were obtained by clinical examination of participants in terms of periodontal health status. The study group included 75 adolescents aged 18, 50 of whom were urban dwellers and 25 were rural dwellers. The study involved 45 males and 30 females. All participants were in good general health and signed a consent form prior to the examination. Dental examinations were carried out by the light of a lamp with a shadow-tube, and with dental mirrors. Periodontal status was assessed on the basis of the CPI. The mouth was divided 
into 6 sextants where, according to the criteria, periodontal status was evaluated. The study was conducted according to the guidelines and diagnostic criteria recommended by the WHO (Oral Health Surveys - Basic Methods, World Health Organization, Geneva. 1997, 4th edn.) [17]. The WHO guidelines evaluated the presence of the plate, bleeding on probing, pocket depth and clinical attachment loss. Periodontal status was assessed using the CPI system: healthy periodontium (code 0 ), bleeding (code 1 ), calculus (code 2) with pockets with a depth of 3.5-5.5 mm (code 3), and a depth of $6 \mathrm{~mm}$ or more (code 4 ), and also excluded from the study (code $\mathrm{x}$ ). Pocket depths were measured using a standard periodontal probe at 6 sites around each representative tooth in each sextant, and represented the distance from the gingival margin to the deepest site of the gingival sulcus. Six sextants containing at least 2 functional teeth were assigned a code number. The condition of the worst-affected site in each sextant was recorded. Periodontal health was transformed from the CPI score to fair (CPI score of 1,2 or 5 ), moderate (CPI score of 3 ) or severe (CPI score of 4) periodontal status [6]. Fair periodontal status was clinically diagnosed as gingivitis, while moderate and severe periodontal statuses were clinically diagnosed as periodontitis.

The results were statistically analyzed and the significance level established at $\mathrm{p}<0.05$. Values of the analyzed parameters were shown by frequencies and percentages.

\section{RESULTS}

50 research participants (66.67\%) lived in the city, and 25 (33.33\%) inhabited rural areas. Among them $60 \%$ were male and $40 \%$ female. Based on the clinical examination, the CPI status was assessed (Fig. 1).

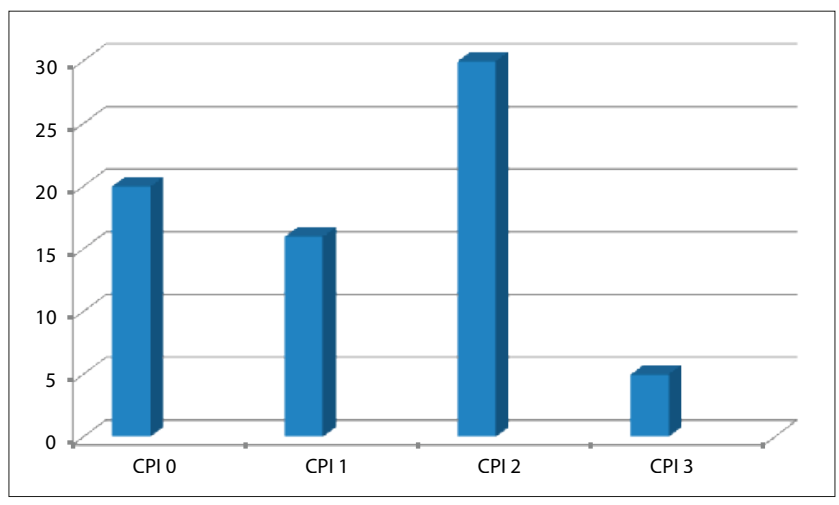

Figure 1. CPI values

In the group of 75 participants, $20(26.66 \%)$ had clinically healthy periodontium (CPI score 0 ). The remaining 55 patients $(73.34 \%)$ had various degrees of periodontal disorders; however, one of them had CPI - 4 (presence of pockets of $>6 \mathrm{~mm}$ ). Most respondents $-40 \%$ (30 persons) were characterized by the presence of calculus over- and subgingival (CPI-2), while 16 patients (21.33\%) showed the presence of bleeding on probing (CPI-1). The presence of pathological periodontal pockets (CPI-3) was found in $6.66 \%$ of patients $(n=5)$.

Periodontal conditions among the participants according to their gender are presented in
Table 1. Valuesof the CPI by gender

\begin{tabular}{lcccc}
\hline Gender & $\mathrm{CPI}=0$ & $\mathrm{CPI}=1$ & $\mathrm{CPI}=2$ & $\mathrm{CPI}=3$ \\
\hline Males & $20.22 \%$ & $34.11 \% *$ & $35.55 \%$ & $3.33 \%$ \\
\hline Females & $36.66 \%$ & $6.66 \%$ & $46.66 \% *$ & $8.88 \%$ \\
\hline Total & $26.66 \%$ & $21.33 \%$ & $40.00 \%$ & $6.66 \%$ \\
\hline
\end{tabular}

* $p<0.5$

By analyzing periodontal health according to gender (Tab. 1), it was noticed that healthy periodontium was present more often among females than males $(36.66 \%$ and $20.22 \%$, respectively). Nonetheless, periodontal lesions were observed among $56.66 \%$ of females and $75.55 \%$ of males. The percentage of participants with bleeding gums (CPI score 1) was $6.66 \%$ of females and $34.11 \%$ of males. The occurrence of calculus (CPI-2) was observed more frequently among females than males ( $46.66 \%$ and $35.55 \%$, respectively; $\mathrm{p}<0.01$ ). The presence of pathological periodontal pockets was found in $3.33 \%$ of females and $8.88 \%$ of males.

Table 2. CPI values with regard to respondents' place of residence

\begin{tabular}{lcccc}
\hline & $\mathrm{CPI}=0$ & $\mathrm{CPI}=1$ & $\mathrm{CPI}=2$ & $\mathrm{CPI}=3$ \\
\hline Urban & $20.00 \%$ & $24.00 \%$ & $44.00 \%$ & $6.00 \%$ \\
\hline Rural & $40.00 \% *$ & $16.00 \%$ & $32.00 \%$ & $8.00 \%$ \\
\hline Total & $26,66 \%$ & $21,33 \%$ & $40.00 \%$ & $6,66 \%$ \\
\hline${ }^{*} \mathrm{p}<0.5$ & & & &
\end{tabular}

More than half of the respondents $(n=56 \%)$ lived in rural areas, and healthy periodontium was observed more frequently among them than urban inhabitants $(40 \%$ and $20 \%$, respectively). $74 \%$ of respondents of urban inhabitants had health problems relating to periodontitis. These differences were statistically significant $(\mathrm{p}<0.5)$. Urban inhabitants exhibited a higher presence of calculus (44\%), bleeding on probing (24\%), and the presence of pathological periodontal pockets (8\%). These differences were not statistically significant.

\section{DISCUSSION}

Periodontal disease and tooth decay are among the most common diseases worldwide [14]. PD is caused by bacterial infections which induce inflammatory responses with progressive destruction of the periodontal tissues, and finally the loss of teeth [6]. PD is usually asymptomatic from gingivitis to periodontitis, but may be characterized by clinical signs and symptoms, including bleeding, tooth shift or loss, periodontal abscesses or halitosis $[1,2,9,11]$. In the acute disease state, untreated inflammation causes pain and bleeding of the gums. The multiplication of bacteria within the tooth plaque leads to tissue destruction and the appearance of pathological periodontal pockets. The ongoing process of inflammation in periodontal tissues causes destruction of the alveolar bone, and then through advancing pockets of bone, tooth loss. [2,11]. In the presented study, 4 patients were excluded from CPI index assessment; however, not as the result of advanced periodontal disease, but the advancement of caries. Epidemiological studies among 18-year-olds conducted from 1995-2012 in Poland, 
show that the youth periodontal status has improved, particularly concerning the presence of plaque. However, it is still problematic as it indicates inadequate dental care $[13,18$, $19,20]$. The survey revealed similar CPI mean values among the respondents. There was a high proportion of young people with the presence of calculus, but statistical analysis showed no significant differences according to gender or place of residence. According to research conducted by Janczuk [21], almost a half of 18 -year-olds had calculus, $39 \%$ of adolescents had periodontal pockets 3-5 $\mathrm{mm}$ deep, and among 0.09\% advanced periodontal diseases were observed. The presented study revealed no presence of pathological pockets (CPI code 4 ), but the number of adolescents with CPI code 3, demonstrating the presence of deep pockets at such a young age, is worrying. Although the study was performed in a single centre with a relatively small research group, it is consistent with previous reports. Comparing the presented results with epidemiological studies [13, 19, 21, 22], a lower incidence of advanced periodontal disease was found.

The results of the study conducted by Struzycka et all [13] showed that more than a third of 18-year-olds have healthy periodontium, and do not require any preventive or treatment methods. Similar values were found in the presented study, and healthier periodontium was observed among young people from rural areas. Similar data were obtained by Skladnik-Jankowska et al. [23] where periodontal diseases were more often reported in young people living in large cities.

Maintaining hygiene and oral health is the most effective way of preventing periodontal diseases. The etiology of periodontal disease is complex; however, it is known that irregular and infrequent tooth brushing increases its risk. Neglecting oral hygiene can lead not only to changes in the tissues of the teeth and gums, but can also cause serious illness in the future $[11,13]$. 18-year-old youths, as a callgroup in the assessment of the masticatory system status, have already formed and fixed oral health behaviours which determine the state of oral health of the adult population [13, 19, 22, 23, 24]. The study of Krawczyk et al. [25] conducted among adolescents from the Lublin region, revealed high values of caries and a low index of treatment which, in turn, demonstrates the need for education among young people aged 16-18.

\section{CONCLUSIONS}

According to the CPI index, as many as $73.4 \%$ of young adults need to undertake preventive actions or initiate treatment for periodontal diseases. These data could be used as a marker of increased risk of periodontal diseases in adults.

\section{REFERENCES}

1.Haładyj A, Borakowska-Siennicka M. Evaluation of knowledge and awareness of patients and physicians on the effect of periodontal disease on cardiovascular disease. New Dentistry 2014, 4, 51-158.
2. Janczuk Z. (ed.). Periodontal disease, prevention diagnosis and treatment. Ed. PZWL, Warszawa 2014 Issue 5, ISBN 97-883-20046-038

3. Franek E, Mountain R. Periodontal disease and cardiovascular health clinical interpretation of the dental examination. Arterial Hypertension 2009, 3, 142-146.

4. Buhlin K, Gustafsson A, Pockley AG. Risk factors for cardiovascular disease in patients with periodontitis. Eur Heart J. 2003; 24: 2099-2107.

5. Mountain R. Association of periodontitis with systemic diseases Dent. Med Probl. 2009; 46: 379-383.

6. Michalowicz BS, Diehl SR, Gunsolley JC, Sparks BS, Brooks CN, Koertge TE, Calfano JV, Burmeister JA, Scheinken HA. Evidence of a substantial genetic basis for risk of adult periodontitis. J Periodontol. 2000, 71, 1699-707.

7. Chambrone L, Guglielmetti MR, Pannuti CM, Chambrone LA. Evidence grade associating periodontitis to preterm birth and/or low birth weight: I. A systematic review of prospective cohort studies. J Clin Periodontol. 2011, 38, 795-808.

8. Materials State Sanitary Inspection "Report on the analysis of survey data from the study eating habits and health of young people in secondary schools," Warsaw 2009.

9. Mountain R. Etiopathogenesis. [in:] Jańczuk Z (ed.). Practical Clinical Periodontology. Ed Quintessence, Warsaw 2004, 23-35.

10. Chaves de Souza JA. Frasnelli SCT. de Almeida Curylofo F. Campos MJA, Spolidorio LC. Zamboni DS, Graves DT, Rossa Junior C. NOD1 in the modulation of host-microbial interactions and inflammatory bone resorption in the periodontal disease model. Immunology 2016. doi: $10.1111 /$ imm.12654

11. Mountain R (ed.). Diseases of the oral cavity - diagnosis and treatment, Urban \& Partner, Wrocław 2006. ISBN 83-89581-49-3.

12. Banach J, Jańczuk Z. Diseases of the oral mucosa and periodontal PZWL Medical Publishing House, Warsaw 2003. ISBN 83-200-2784-5.

13. Struzycka I, Wierzbicka M, Jodkowska E, Rusyan E, Ganowicz M, Ziemięcka K. Performance Condition Monitoring Oral Health young adult population in Poland in 2012. New Dentistry 2013; 4: 195-199.

14. Mountain R, Pietruska M, Dembowska-Wysokińska E. Miszczuk J, Włosowicz M, Konopka T. The prevalence of periodontal disease in people aged 35-44 years in the population of large urban agglomerations. Dent Med Probl. 2012; 49: 19-27.

15. Muszyński R, Ziaja M. The status and periodontal treatment needs in people 35-44-year-old from the province of Katowice. Time. Stomata. 2000, 97-102.

16. Stawicka R, Mountain R. The influence of genetic factors on the occurrence of periodontal disease. New Stomatology 1999; 3: 21-22.

17. World Health Organization. Oral health surveys - basic methods. Geneva, 4th edn. 1997.

18. Mielnik-Błaszczak M, Krawczyk D, Stachurski P. Evaluation of dentition in patients aged 15 and 18 years in a region of south-eastern Polish (Podkarpackie Province). New Dentistry 2013; 1: 26-30.

19. Cwiklak K, Pypeć J, Pijankowska-Beksa L, Szczepańska J. Analysis of health behavior of young people 18 years of attending school in Lodz. New Dentistry 2011; 3: 91-96.

20. Jodkowska E. Public program for the prevention of dental caries in Poland in children and adolescents. Dent Med Probl. 2010; 47: 137-143.

21. Janczuk Z. The needs and possibilities of prevention of dental caries and periodontal disease in the Polish youth. Mag Stomatological 2002; 4: $35-38$.

22. Emerich-Poplatek K, Adamowicz-Klepalska B, Sawicki L. Oral Health 18-year-olds with a Pomeranian province in the study in 2003. Dent Med Probl. 2004; 41: 427-432.

23. Component-Jankowska J, Kaczmarek U. Periodontal status in children and adolescents from the province of Lower Silesia. Dent Med Probl. 2013; 50: 167-177.

24. Grubbs V, Vittinghoff E, Taylor G, Kritz-Silverstein D, Powe N, BibbinsDomingo K, Ishani A, Cummings SR. Osteoporotic Fractures in Men (MrOS) Study Research Group. Nephrol Dial Transplant. 2016; 31: 466-72.

25. Krawczyk D, Pels E, Jedrych M, Błaszczak J. Evaluation of the state of dentition in children and adolescents aged 16-18 attending secondary schools in the city of Lublin. Zdr Publ. 2012; 122: 58-60. 